\title{
RANCANG BANGUN PROTOTYPE SMART HOME DENGAN KONSEP INTERNET OF THINGS (IOT) MENGGUNAKAN RASPBERRY PI BERBASIS WEB
}

\author{
Bagus Eryawan $^{1}$, Ari Endang Jayati ${ }^{2}$, dan Sri Heranurweni ${ }^{3)}$ \\ ${ }^{1,2,3)}$ Program Studi Teknik Elektro, Fakultas Teknik, Universitas Semarang \\ Jalan Soekarno Hatta - Tlogosari, Semarang, Indonesia, 50196 \\ e-mail: eryawan@gmail.com ${ }^{1)}$, ariendang@usm.ac.id ${ }^{2)}$, heranur@usm.ac.id ${ }^{3)}$
}

\begin{abstract}
High economic growth makes the demand for comfortable and safe houses increase and the application of technology that is most clearly seen is technology with automatic systems. With this technology, the use of electricity in the house can be minimized and offer convenience in controlling the house. Sometimes homeowners forget to turn off the lights when they are outside the house so they have to go back and do checks that are very inefficient both in terms of time and financially such as the cost of gasoline to return to the house.

Based on this, the Smart Home Prototype was created with the concept of the Internet of Things (IoT) using Raspberry Pi Web-Based, which is a system that can remotely control electronic home appliances using Raspberry Pi as a base system, which is connected to Web Applications through the internet network. The electronic equipment used in this study is in the form of 5 lamps, 1 stepper motor to control the garage, 1 servo motor to control the door lock, and 1 brushless motor that functions as a fan.

Blocking and overall test results on Bedroom Lights, Living Room Lights, Kitchen Lights, Bathroom Lights, Porch Lights, Garages, Door Locks, and Fans, all work well. The testing of the distance between cities against the Prototype Smart Home was successfully carried out, where the Prototype Smart Home in the City of Demak was successfully controlled by the User who at the time of testing was in the City of Semarang, Kudus, Japan, Surabaya, and Jakarta.
\end{abstract}

Keywords: Smart Home, Raspberry Pi, Internet of Things, Aplikasi Web

\begin{abstract}
ABSTRAK
Pertumbuhan ekonomi yang tinggi membuat permintaan akan rumah yang nyaman dan aman kian meningkat dan penerapan teknologi yang paling jelas terlihat adalah teknologi dengan sistem otomatis. Dengan teknologi ini, penggunaan listrik pada rumah bisa terminimalisir dan menawarkan kemudahan dalam mengontrol rumah. Terkadang pemilik rumah lupa untuk mematikan lampu ketika sedang berada di luar rumah sehingga harus kembali dan melakukan pengecekan yang sangat tidak efisien baik dari sisi waktu maupun finansial seperti biaya bensin untuk kembali lagi ke rumah.

Berdasarkan hal tersebut maka dibuatlah Prototype Smart Home Dengan Konsep Internet of Things (IoT) menggunakan Raspberry Pi Berbasis Web, yaitu sebuah sistem yang dapat mengontrol peralatan elektronik rumah dari jarak jauh menggunakan Raspberry Pi sebagai basis sistem, yang terhubung dengan Aplikasi Web melalui jaringan internet. Peralatan elektronik yang digunakan pada penelitian ini berupa 5 buah Lampu, 1 buah Motor Stepper untuk mengendalikan Garasi, 1 buah Motor Servo untuk mengendalikan kunci pintu, dan 1 buah Motor Brushless yang berfungsi sebagai kipas angin.

Hasil Pengujian perblok maupun secara keseluruhan pada Lampu Kamar Tidur, Lampu Ruang Tamu, Lampu Dapur, Lampu Kamar Mandi, Lampu Teras, Garasi, Kunci Pintu, dan Kipas Angin, semuanya dapat bekerja dengan baik. Pengujian jarak kendali antar kota terhadap Prototype Smart Home berhasil dilakukan, dimana Prototype Smart Home yang berada di Kota Demak berhasil dikendalikan oleh User yang pada saat pengujian berada di Kota Semarang, Kudus, Jepara, Surabaya, dan Jakarta.
\end{abstract}

Kata Kunci: Smart Home, Raspberry Pi, Internet of Things, Aplikasi Web

\section{Pendahuluan}

$\mathrm{T}$ lerkadang pemilik rumah lupa untuk mematikan lampu ketika sedang berada di luar rumah sehingga harus kembali dan melakukan pengecekan yang sangat tidak efisien baik dari sisi waktu maupun finansial seperti biaya bensin untuk kembali lagi ke rumah. Dengan tujuan efisiensi itulah penulis mencoba untuk merancang sebuah Sistem Smart Home yang dapat dikontrol dari jarak jauh.

Sistem Smart Home ini dirancang agar pemilik rumah dapat mengontrol semua bagian yang ada di rumahnya dengan menggunakan sistem yang terintegrasi ke internet. Hal tersebut bertujuan untuk memberikan keamanan dan kenyamanan bagi pemilik rumah dan orang-orang yang tinggal didalamnya, karena dapat memudahkan pekerjaan agar menjadi lebih cepat, efektif, dan efisien.

Internet of Things (IoT) merupakan sebuah konsep yang bertujuan untuk memperluas manfaat dari konektivitas internet, IoT sendiri sudah diperkenalkan pertama kali oleh Kevin Ashton dalam presentasinya 
"Co-Founder and Executive Director of The Auto-ID Center" di MIT pada tahun 1999. Namun kenyataannya konsep Internet of Things khususnya di Indonesia belum diterapkan secara maksimal.

Penelitian tentang perancangan IoT pada smart home telah banyak dilakukan. Penelitian tentang sistem Pengontrol Lampu Rumah Berbasis Raspberry P $i$ telah dilakukan [1]. Erwinnanto telah melakukan perancangan Smart Home Automatic Control dengan komunikasi melalui Bluetooth HC-05 berbasis Mikrokontroler Arduino dan Android [2]. Pada penelitian ini akan menerapkan konsep Internet of Things (IoT) pada Smart Home atau rumah pintar. Juga akan dibuat aplikasi yang dapat mengontrol peralatan elektronik rumah melalui internet serta membuat tampilan antarmuka control panel berbasis website dan hanya dapat diakses oleh orang yang berhak (authentication user). Prototype ini diharapkan dapat menjadi bahan pertimbangan seseorang dalam menerapkan konsep Smart Home dan Internet of Things di kehidupan nyata.

Organisasi dari paper ini adalah: Seksi II menjelaskan tentang model sistem yang digunakan, Seksi III membahas perancangan prototype Smart Home dengan Raspberry Pi. Pada seksi IV membahas tentang hasil pengujian perancangan prototype yang dibuat, selanjutnya Seksi V adalah kesimpulan.

\section{Model Sistem}

\subsection{Internet of Things}

Internet of Things atau dikenal juga dengan singkatan IoT merupakan sebuah konsep yang bertujuan untuk memperluas manfaat dari konektivitas internet yang tersambung secara terus-menerus. Istilah Internet of Things mulai dikenal tahun 1999 yang saat itu disebutkan pertama kalinya dalam sebuah presentasi oleh Kevin Ashton, cofounder and executive director of the Auto-ID Center di MIT [3].

Dengan menggunakan Internet of Things memungkinkan suatu sistem dapat dikendalikan secara otomatis tanpa mengenal jarak melalui jaringan Internet. Pengimplementasian Internet of Things sendiri selalu mengikuti keinginan dari Developer dalam mengembangkan sebuah aplikasi. Apabila aplikasi yang diciptakan adalah untuk memonitoring dan mengontrol peralatan elektronik pada sebuah rumah, maka diperlukan suatu perangkat yang dapat menghubungkan peralatan elektronik dengan Website Control. Salah satu contoh perangkat yang dapat menghubungkan peralatan elektronik dengan Website Control adalah Raspberry $P i$. Selain itu, penambahan sensor akan membuat peralatan elektronik dapat berjalan secara otomatis.

\subsection{Raspberry Pi}

Raspberry $P i$ adalah sebuah mini computer yang berukuran sebesar kartu kredit yang dibuat di Inggris oleh Raspberry Pi Fondation [4-5]. Raspberry Pi mampu menjalankan berbagai aplikasi dan software layaknya sebuah Personal Computer dengan kebutuhan daya listrik yang cukup kecil yaitu 5 Volt. Mini Computer ini dibuat dengan tujuan untuk meningkatkan minat anak kecil terhadap programing [1]. Gambar 1 adalah Raspberry Pi 3 Model B.

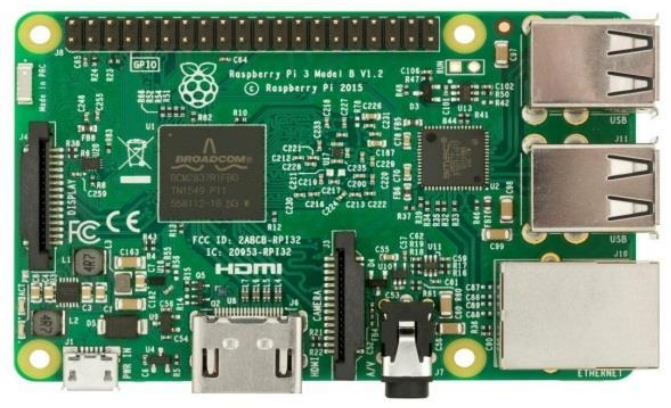

Gambar. 1. Raspberry Pi 3 Model B [5]

\section{Perancangan}

Sistem dibangun dalam bentuk prototype atau purwarupa. Menggunakan Raspberry Pi 3 model B sebagai pusat pengendali peralatan elektronik. Control Panel dibuat berbasis Website yang terintegrasi dengan jaringan internet melalui Hosting dan Domain. Akses Website melalui proses authentication user terlebih dahulu. Pengendalian perangkat elektronik yang dilakukan hanya sebatas On / Off. Perangkat elektronik yang diuji coba pada aplikasi ini adalah 5 buah lampu, 1 buah motor brushless yang berfungsi sebagai kipas angin, 1 buah motor servo untuk mengendalikan kunci pintu, dan 1 buah motor stepper untuk mengendalikan garasi rumah.

\subsection{Diagram Blok}

Dari Gambar 2, dapat dijelaskan bahwa untuk dapat mengendalikan Prototype Smart Home pertama-tama User harus mengakses Website terlebih dahulu melalui User Interface, baik menggunakan Laptop, Smartphone atau yang lainnya, dengan syarat User Interface yang digunakan dapat terkoneksi dengan jaringan internet. Setelah Website berhasil diakses User dapat melakukan perubahan status $O N$ dan $O F F$ pada Lampu Kamar Tidur, Lampu Ruang Tamu, Lampu Dapur, Lampu Kamar Mandi, Lampu Teras, OPEN dan CLOSE pada Garasi, UNLOCK dan LOCK pada Kunci Pintu, serta $O N$ dan $O F F$ pada Kipas Angin. Perubahan status ini akan menghasilkan kode berupa angka yang berbedabeda, yang kemudian kode tersebut akan disimpan pada database dan file status_control.txt yang berada di dalam Website.

Agar Raspberry Pi dapat mengakses Website ketika program dijalankan, maka perlu adanya koneksi antara Raspberry Pi dengan Wifi Access. Wifi Access merupakan suatu perangkat yang digunakan untuk menghubungkan Raspberry $P i$ dengan jaringan internet, 
perangkat tersebut dapat berupa Mobile Wifi atau Hotspot Smartphone [6-7]. Apabila Raspberry Pi sudah berhasil mengakses Website, selanjutnya Raspberry Pi akan membaca dan memproses kode yang tersimpan di dalam file status_control.txt, kemudian akan diteruskan ke Relay 1 untuk mengendalikan Lampu Kamar Tidur, Relay 2 untuk mengendalikan Lampu Ruang Tamu, Relay 3 untuk mengendalikan Lampu Dapur, Relay 4 untuk mengendalikan Lampu Kamar Mandi, Relay 5 untuk mengendalikan Lampu Teras, Motor Stepper untuk mengendalikan Garasi, Motor Servo untuk mengendalikan Kunci Pintu, dan Motor Brushless untuk mengendalikan Kipas Angin [8-10].

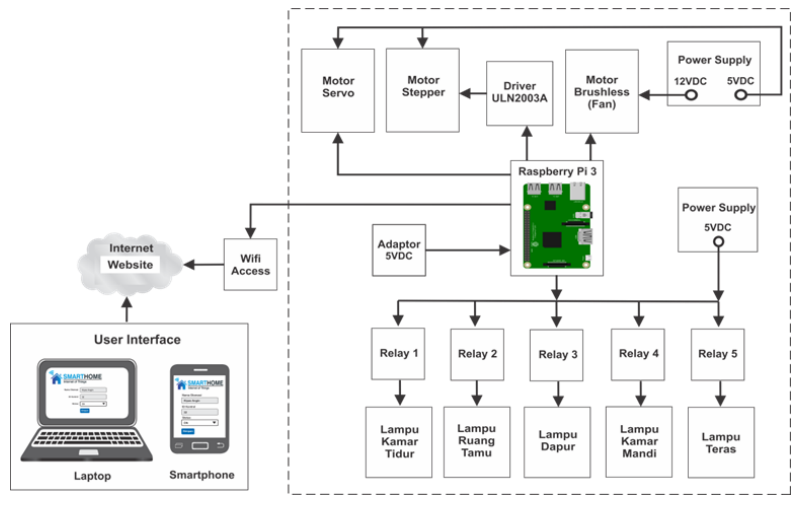

Gambar. 2. Diagram Blok

\section{Hasil Pengujian}

Hasil pengujian rancang bangun prototype Smart Home menggunakan Raspberry Pi melalui berbagai cara. Pengujian akses website melalui laptop dan smartphone. Juga dilakukan pengujian setiap komponen dari prototype rancang bangun ini.

\subsection{Pengujian Akses Website Melalui Laptop dan Smartphone.}

Tujuan dari pengujian ini adalah untuk mengetahui apakah Website Smart Home dapat diakses melalui Laptop, Smartphone dan perangkat komunikasi lainnya. Hasil pengujian ditunjukkan pada Gambar 3-5.

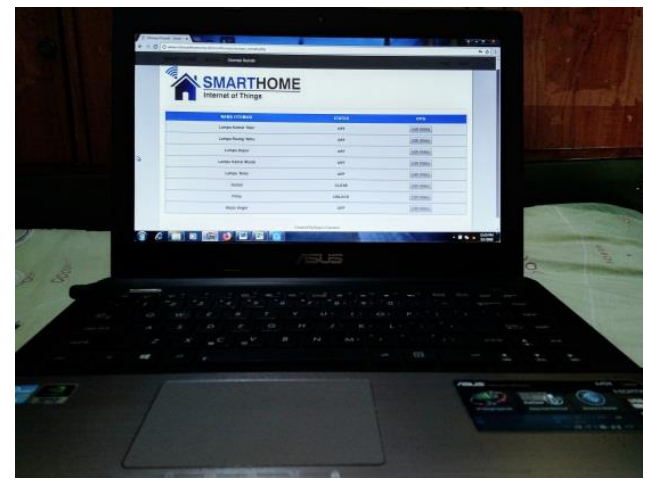

Gambar. 3. Pengujian Akses Website Melalui Laptop ASUS A45V

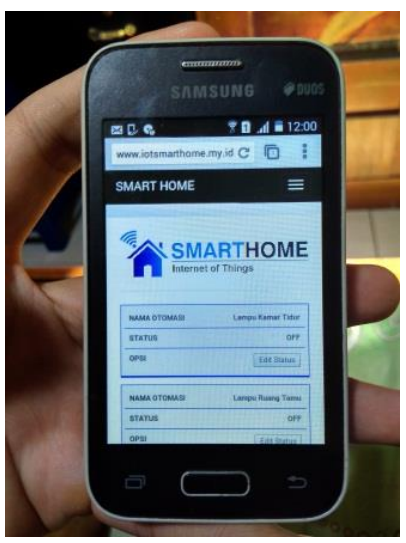

Gambar. 4. Pengujian Akses Web Melalui Smarthphone Samsung Galaxy Young 2

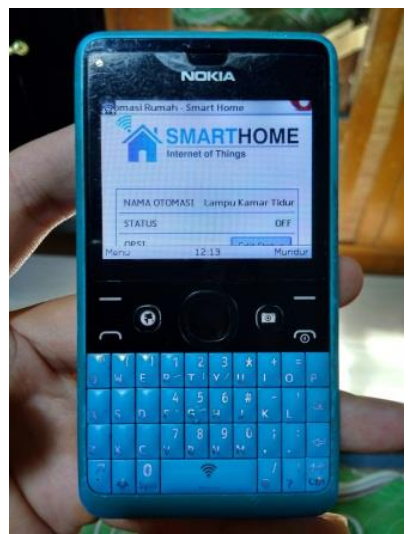

Gambar. 5. Pengujian Akses Website Melalui Handphone Nokia Asha 210

Berdasarkan Pengujian Akses Website yang sudah dilakukan, diperoleh hasil Website Smart Home dapat diakses melalui Laptop ASUS A45V, Smartphone Android Samsung Galaxy Young 2, dan Handphone Nokia Asha 210.

\subsection{Pengujian Power Supply}

Pengujian berikutnya adalah pengujian pada komponen prototype yaitu pada bagian power supply yang ditunjukkan pada Tabel 1.

TABEL I

HASIL PENGUJIAN POWER SUPPLY

\begin{tabular}{lllc}
\hline $\begin{array}{l}\text { Power Sup- } \\
\text { ply Untuk }\end{array}$ & $\begin{array}{l}\text { IC Regula- } \\
\text { tor }\end{array}$ & $\begin{array}{l}\text { Target } \\
\text { (Volt) }\end{array}$ & $\begin{array}{l}\text { Hasil Penguku- } \\
\text { ran (Volt) }\end{array}$ \\
\hline $\begin{array}{l}\text { Rangkaian } \\
\begin{array}{l}\text { Switching } \\
\text { Lampu }\end{array}\end{array}$ & LM7805 & 5 & 5,06 \\
\hline $\begin{array}{l}\text { Rangkaian } \\
\text { Motor DC }\end{array}$ & LM7805 & 5 & 5,04 \\
\cline { 2 - 4 } & LM7812 & 12 & 11,78 \\
\hline
\end{tabular}


Berdasarkan hasil pengujian yang sudah dilakukan, setiap Power Supply pada penelitian ini mempunyai toleransi penyimpangan tegangan kurang dari $2 \%$ dari batas 4\%. Sehingga Power Supply tersebut diperbolehkan untuk digunakan.

\subsection{Pengujian Rangkaian Switching Lampu}

TABEL II

HASIL PENGUJIAN RANGKAIAN SWITCHING LAMPU

\begin{tabular}{|c|c|c|c|}
\hline \multirow{2}{*}{ Nama Otomasi } & \multirow{2}{*}{$\begin{array}{l}\text { Status Con- } \\
\text { trol Web- } \\
\text { site }\end{array}$} & \multicolumn{2}{|c|}{ Pengujian Lampu } \\
\hline & & Kondisi & Tegangan (Volt) \\
\hline \multirow{2}{*}{$\begin{array}{l}\text { Lampu } \\
\text { Tidur }\end{array}$} & $O N$ & Menyala & 219 \\
\hline & $O F F$ & Padam & 0 \\
\hline \multirow{2}{*}{$\begin{array}{l}\text { Lampu } \\
\text { Tamu }\end{array}$} & $O N$ & Menyala & 218 \\
\hline & $O F F$ & Padam & 0 \\
\hline \multirow{2}{*}{ Lampu Dapur } & $O N$ & Menyala & 219 \\
\hline & $O F F$ & Padam & 0 \\
\hline \multirow{2}{*}{$\begin{array}{l}\text { Lampu } \\
\text { Mandi }\end{array}$} & $O N$ & Menyala & 219 \\
\hline & $O F F$ & Padam & 0 \\
\hline \multirow{2}{*}{ Lampu Teras } & ON & Menyala & 218 \\
\hline & OFF & Padam & 0 \\
\hline
\end{tabular}

Berdasarkan pengujian Rangkaian Switching Lampu yang sudah dilakukan, diperoleh hasil seperti Tabel 2 yaitu ketika Status Control Website ON maka lampu menyala, sebaliknya ketika Status Control Website OFF maka lampu padam. Selain itu juga diketahui tegangan yang terukur ketika lampu menyala sebesar 218VAC 219VAC, sedangkan tegangan yang terukur ketika lampu padam sebesar 0VAC. Dari hasil pengujian tersebut dapat disimpulkan bahwa lampu pada masingmasing blok dapat bekerja dengan baik.

\subsection{Pengujian Rangkaian Motor Stepper}

TABEL III

HASIL PENGUJIAN GARASI

\begin{tabular}{ccc}
\hline $\begin{array}{l}\text { Status Control } \\
\text { Website }\end{array}$ & $\begin{array}{l}\text { Kondisi Gar- } \\
\text { asi }\end{array}$ & $\begin{array}{l}\text { Tegangan Driver ULN2003A } \\
\text { (Volt) }\end{array}$ \\
\hline OPEN & Terbuka & 4,42 \\
\hline CLOSE & Tertutup & 4,58 \\
\hline
\end{tabular}

Berdasarkan pengujian Rangkaian Motor Stepper yang sudah dilakukan, diperoleh hasil seperti ditunjukkan Tabel 3, yaitu ketika Status Control Website OPEN maka Garasi terbuka, sebaliknya ketika Status Control Website CLOSE maka Garasi tertutup. Selain itu juga diketahui tegangan yang terukur pada Driver ULN2003A ketika Garasi terbuka sebesar 4,42 Volt, sedangkan tegangan yang terukur pada Driver ULN2003A ketika Garasi tertutup sebesar 4,58 Volt.
Beban yang diangkat pada saat Garasi terbuka lebih berat dibandingkan saat Garasi tertutup, sehingga membuat rugi-rugi tegangan pada saat Garasi terbuka lebih besar daripada saat Garasi tertutup.

\subsection{Pengujian Rangkaian Motor Servo}

Berdasarkan pengujian Rangkaian Motor Servo yang sudah dilakukan, diperoleh hasil seperti Tabel 4, yaitu ketika Status Control Website UNLOCK maka poros pada Motor Servo berputar sebanyak $90^{\circ}$ kearah kanan sehingga membuat Pintu tidak terkunci, sebaliknya ketika Status Control Website LOCK maka poros pada Motor Servo kembali ke posisi $0^{\circ}$ sehingga membuat Pintu terkunci. Dari hasil pengujian tersebut dapat disimpulkan bahwa Motor Servo dapat bekerja dengan baik.

TABEL IV

HASIL PENGUJIAN KUNCI PINTU

\begin{tabular}{clcc}
\hline $\begin{array}{l}\text { Status Con- } \\
\text { trol Website }\end{array}$ & $\begin{array}{l}\text { Kondisi } \\
\text { Pintu }\end{array}$ & $\begin{array}{l}\text { Posisi } \\
\text { Poros } \\
\text { Motor } \\
\text { Servo }\end{array}$ & $\begin{array}{l}\text { Pengukuran Tegangan Mo- } \\
\text { tor Servo (Volt) }\end{array}$ \\
\hline LOCK & Terkunci & $0^{\circ}$ & 4,98 Volt \\
\hline UNLOCK & $\begin{array}{l}\text { Tidak } \\
\text { Terkunci }\end{array}$ & $90^{\circ}$ & 4,97 Volt \\
\hline
\end{tabular}

\subsection{Pengujian Rangkaian Motor Brushless (Fan)}

TABEL V

HASIL PENGUJIAN KIPAS ANGIN

\begin{tabular}{|c|c|c|}
\hline \multirow{2}{*}{$\begin{array}{l}\text { Status Control } \\
\text { Website }\end{array}$} & \multicolumn{2}{|l|}{ Kondisi } \\
\hline & Kipas Angin & Tegangan (Volt) \\
\hline$O N$ & Berputar & 11,74 Volt \\
\hline$O F F$ & Tidak Berputar & 0 Volt \\
\hline
\end{tabular}

Berdasarkan pengujian Rangkaian Motor Brushless yang sudah dilakukan, diperoleh hasil seperti Tabel 5, yaitu ketika Status Control Website ON maka Motor Brushless berputar, sebaliknya ketika Status Control Website OFF maka Motor Brushless tidak berputar. Selain itu juga diketahui tegangan yang terukur pada Motor Brushless ketika berputar sebesar 11,74 Volt, sedangkan tegangan yang terukur pada Motor Brushless ketika tidak berputar sebesar 0 Volt. Dari hasil pengujian tersebut dapat disimpulkan bahwa Motor Brushless dapat bekerja dengan baik.

\subsection{Pengujian Jarak Kendali Prototype Smart Home}

Pada pengujian ini penulis melakukan pengujian jarak kendali antar kota, dimana Prototype Smart Home yang berada di rumah Penulis di kota Demak dapat 
dikendalikan oleh teman dan kerabat penulis yang pada saat pengujian ini berada di luar dari kota penulis.

Berdasarkan Pengujian Jarak Kendali Prototype Smart Home yang sudah dilakukan, diperoleh hasil seperti table 6, yaitu bahwa Lampu Kamar Tidur, Lampu Ruang Tamu, Lampu Dapur, Lampu Kamar Mandi, Lampu Teras, Garasi, Kunci Pintu, dan Kipas Angin dapat dikendalikan dengan lancar dari luar kota atau tempat dimana teman dan kerabat penulis berada.

TABEL VI

HASIL PENGUJIAN JARAK KENDALI PROTOTYPE SMART HiOME

\begin{tabular}{cll}
\hline $\begin{array}{l}\text { Posisi Prototype } \\
\text { Smart Home }\end{array}$ & Posisi User & Hasil Pengendalian \\
\hline Demak & Semarang & Lancar \\
\hline Demak & Kudus & Lancar \\
\hline Demak & Jepara & Lancar \\
\hline Demak & Surabaya & Lancar \\
\hline Demak & Jakarta & Lancar \\
\hline
\end{tabular}

\section{KESIMPULAN}

Pada penelitian ini telah behasil membuat sebuah Prototype Smart Home dengan konsep Internet of Things (IoT) menggunakan Raspberry Pi berbasis Web. Website Smart Home dapat diakses melalui berbagai perangkat komunikasi, dengan syarat perangkat komunikasi tersebut harus memiliki jaringan internet dan web browser. Power Supply yang digunakan pada Rangkaian Motor DC maupun pada Rangkaian Switching Lampu mempunyai toleransi penyimpangan tegangan kurang dari $2 \%$ dari batas 4\%, sehingga Power Supply tersebut diperbolehkan untuk digunakan. Setelah dilakukan pengujian pada Rangkaian Switching Lampu, Rangkaian Motor Stepper, Rangkaian Motor Servo, dan Rangkaian Motor Brushless (Fan), diperoleh hasil semuanya dapat bekerja dengan baik. Berhasil dilakukannya pengujian jarak kendali antar kota terhadap Prototype Smart Home, dimana Prototype Smart Home yang berada di kota Demak dapat dikendalikan oleh User yang pada saat pengujian berada di kota Semarang, Kudus, Jepara, Surabaya, dan Jakarta. Dengan menerapkan konsep Internet of Things (IoT), Prototype Smart Home dapat dikendalikan dari jarak yang sangat jauh melalui Website yang sudah terintegrasi dengan jaringan internet. Penelitian selanjutnya adakah penambahan jadwal $O N$ dan $O F F$ secara otomatis pada lampu agar User tidak perlu lagi melakukan pengontrolan secara manual melalui Website. Selain itu juga penambahan kamera pada Prototype Smart Home akan sangat membatu User dalam memantau kondisi Prototype
Smart Home setiap saat. Juga akan ditambah pemasangan berbagai macam sensor untuk membuat Prototype Smart Home dapat berjalan secara otomatis.

\section{DAFTAR PUSTAKa}

[1] Christoper Sidabutar, Bob. 2016. Sistem Pengontrol Lampu Rumah Berbasis Raspberry Pi. Universitas Widyatama.

[2] Erwinnanto, Yohan. 2016. Rancang Bangun Smart Home Automatic Control dengan Komunikasi Melalui Bluetooth HC-05 Berbasis Mikrokontroler Arduino dan Android. Universitas Semarang.

[3] Yudhanto, Yudha. 2007. Apa itu IOT (Internet Of Things). Universitas Sebelas Maret.

[4] Kadir, Abdul. 2016. Dasar Raspberry Pi - Panduan Praktis Untuk Mempelajari Pemrograman Perangkat Keras Menggunakan Raspberry $P i$ Model B. Yogyakarta: Penerbit Andi.

[5] R.P. Foundation, "Raspberry Pi", Raspberry Pi Foundation (online). (https://www.raspberrypi.org/help/faqs/ diakses 12 Maret 2018).

[6] Miono. 2013. Perancangan Sistem Informasi dan Aplikasi Pengelolaan Barang Kios F-Three Dengan Teknologi Berbasis Web XAMPP. Universitas Sebelas Maret.

[7] Saputro, Hendra W. 2007. Pengertian Website dan Unsur-unsurnya (online). (https://balebengong.id/teknologi/pengertianwebsite-dan-unsur-unsurnya. html diakses 12 Maret 2018).

[8] Julianto, Daniel. 2017. Media Pembelajaran Trainer Motor DC, Brushless, Servo, dan Stepper Dengan Kendali Mikrokontroler Arduino Uno Pada Mata Pelajaran Teknik Mikroprosesor Di SMK Negeri 2 Depok Yogyakarta. Universitas Negeri Yogyakarta.

[9] Nanda Prakasa, Guntur. 2017. Prototipe Kunci Pintu Menggunakan Motor Stepper Berbasis $\mathrm{Ar}$ duino Mega 2560 Dengan Perintah Suara Pada Android. Universitas Lampung.

[10] Pujiono, Aris. 2014. Pemasangan Motor DC Pada Sekuter Dengan Pengendali Pulse Width Modulation. Universitas Muhammadiyah Surakarta. 